\title{
A IMPORTÂNCIA DO PLANEJAMENTO E ORCAMENTO: UM ESTUDO DE CASO SOBRE O USO DA FERRAMENTA DE ORÇAMENTO EM UM CONDOMÍNIO.
}

\section{IMPORTANCE OF A PLANNING AND BUDGET: A CASE STUDY ON THE BUDGET TOOL USED IN A CONDOMINIUM}

\author{
Recebido: 26/12/2014 - Aprovado: 06/04/2015 - Publicado: 15/05/2015 \\ Processo de Avaliação: Double Blind Review
}

\author{
Eduardo Roberto Priore ${ }^{1}$ \\ Mestre em Administração pela Universidade Metodista de São Paulo \\ Professor e Coordenador do Centro Universitário Estácio Radial de São Paulo \\ Claudia Rosa de Moura Velozo \\ Mestranda em Administração pela Universidade Paulista - UNIP \\ Professora e Coordenadora do Centro Universitário Estácio Radial de São Paulo \\ Paula Itiko Hikazudani \\ Graduando em Administração de Empresas \\ Centro Universitário Estácio Radial de São Paulo \\ Zuleide Rosa Moura de Andrade \\ Graduando em Administração de Empresas \\ Centro Universitário Estácio Radial de São Paulo
}

\section{RESUMO}

O presente estudo aborda a importância de utilizar os conhecimentos de planejamento e orçamento em qualquer entidade ou instituição, independente do objetivo a ser atingido. No assunto abordado deixou-se claro que administrar qualquer instituição às cegas, ou seja, sem qualquer técnica administrativa, sem critérios deixa à instituição a sorte do acaso. Visando evitar descompasso no planejamento executado é imprescindível lançar mão de uma reserva para contingências, desta forma caso haja uma despesa de maior valor se manterá dentro de um patamar aceitável.

Palavras-chave: Planejamento; Orçamento Empresarial; Técnicas Administrativas.

\begin{abstract}
This study addresses the importance of using the knowledge of planning and budgeting in any entity or institution, regardless of the purpose to be achieved. This content applied in the case study, demonstrating the results of the correct application of the budget methodology. In the subject matter made it clear that administer any institution blindly, ie without any administrative procedure without criteria leaves the institution the sort of chance. To avoid the mismatch in the planning run one must make use of a reserve for contingencies, so if there is a higher value expenditure will remain within an acceptable level.
\end{abstract}

\footnotetext{
${ }^{1}$ Autor para correspondência: Centro Universitário Estácio Radial de São Paulo - Avenida Jabaquara, 1870 Saúde - São Paulo - SP, Brasil, CEP 04046-300.
} 
Keywords: Planning; Budget Business; Administrative Techniques.

\section{INTRODUÇÃO}

O planejamento é a chave da gestão empresarial para as pequenas empresas, grandes corporações, agências governamentais, organizações sem fins lucrativos ou simplesmente para a vida pessoal dos indivíduos (LEITE et. al., 2008, p. 57). Todos os gestores fazem rotineiramente algum tipo de planejamento. Apesar de nas pequenas organizações esta prática não ser aplicada com um modelo formal.

"O planejamento financeiro é um aspecto importante da empresa porque oferece orientação para a direção, à coordenação e controle das providências tomadas pela organização para que atinja seus objetivos" (GITMAN, 2004, p. 94).

Diante da expansão comercial os modelos informais não são suficientes, obrigando as organizações a planejarem as estratégias, objetivos e metas de modo a garantir o crescimento e riqueza do negócio como um todo, preservando o patrimônio e aumentando-os a medida de sua evolução.

\section{A IMPORTÂNCIA DO PLANEJAMENTO E ORÇAMENTO}

Por meio do orçamento é possível visualizar e medir o crescimento da organização, formalizando objetivos e metas de forma clara e transparente, facilitando o gestor uma rápida análise das situações diárias e periódicas.

\footnotetext{
O orçamento empresarial não deve ser entendido como instrumento limitador e controlador de gastos, mas como forma de focalizar a atenção nas operações e finanças da empresa, antecipando os problemas, sinalizando metas e objetivos que necessitem de cuidado por parte dos gestores, contribuindo para a tomada de decisões com vistas ao atendimento da missão e do cumprimento das estratégias das empresas (LEITE et al., 2008 p. 57).
}

Diante da competitividade acirrada, as organizações se vêem na obrigação de ter seus custos e procedimentos sob controle efetivo e dinâmico, evitando surpresas que possam desestruturar as finanças ou colocar em risco o seu mercado ou liderança.

Com a ampla divulgação de informações, os consumidores tornaram-se mais exigentes e escolhem sempre os produtos de melhor qualidade com custo compatível, gerando grande competitividade entre as organizações, que por sua vez, inovam o mercado com lançamentos cada vez mais elaborados e com custo reduzido. 
As organizações diante de seu crescimento veloz, busca no mercado profissional habilitado e com grande conhecimento na intenção de controlar de perto a evolução de seu patrimônio, apesar dos sócios ou investidores não estarem tão próximos à administração.

A área contábil enfatiza que a importância do sucesso empresarial está intimamente ligada a um processo de controle e planejamento da organização, desde o esboço até a concretização do negócio, quando se inicia a definição das estratégias e missão, das quais as organizações vão lutar para atingir. Estas estratégias precisam ser formalizadas através de uma definição financeira e controladas pelo processo orçamentário.

Algumas vantagens podem ser obtidas com a adoção de medidas de controle, tais como o orçamento. Uma administração bem estruturada respeitará as medidas demonstradas em seus relatórios, utilizando apenas os recursos que estiverem disponíveis e jamais ultrapassarão a medida de segurança estabelecida pelo seu administrador ou gestor e Leite et al. (2008, p. 57) afirma que "outros benefícios podem ser obtidos com a implantação do orçamento, por exemplo, rigor no controle do fluxo de caixa.

\section{REVISÃO BIBLIOGRÁFICA}

Planejamento é uma ferramenta que viabiliza ações futuras. É a estruturação das idéias de forma ordenada, buscando o melhor resultado projetado. Planejar significa antever ou simular os objetivos a fim de visualizar o seu resultado em forma de previsão. Usamos o planejamento em nosso dia a dia sem perceber, pois é através dele que programamos as nossas atividades com o objetivo de otimizar os recursos disponíveis, sempre na busca do melhor resultado possível.

Planejar é uma estratégia para aumentar as chances de sucesso de uma empresa em um mundo de negócios que muda constantemente. Planos estratégicos não são garantia de sucesso o planejamento estratégico será tão eficaz quanto as premissas que foram nele incluídas (PADOVEZE, 2012, p. 101)

O planejamento é peça fundamental na gestão de toda e qualquer organização. É uma ferramenta que organiza, prepara e estrutura as tomadas de decisão. Com o aumento da competitividade entre as empresas, as alterações e mudanças no planejamento e constante, pois, visa garantir que a empresa permaneça competitiva e atuante.

As organizações contemporâneas atuam em ambientes cada vez mais dinâmicos, complexos e competitivos. Nesse contexto, para sobreviver, as organizações necessitam de um rumo de uma direção. É por meio do planejamento que os administradores definem para onde a organização deve caminhar e como lá chegar. (SOBRAL e PECI, 2008, p. 131). 
Para que o administrador tenha um bom desempenho é necessário prever as mudanças, antecipando as providencias. A incerteza é constante no dia a dia das organizações e é relevante que os administradores reflitam sobre a importância do planejamento e das estratégias.

A divulgação do planejamento foi fundamental para que as organizações tivessem consciência de sua importância. O planejamento é base para que se possa escolher um destino, sempre avaliando as escolhas e definindo o rumo das estratégias escolhidas para atingir o seu objetivo e destino. Planejar significa estudar a fundo as metas traçadas pela empresa, escolhendo as ferramentas necessárias, o tempo certo para sua aplicação, prevendo o momento exato para sua implantação. Todas estas as medidas visam formar uma base para as medidas que serão tomadas, na tentativa de prever o seu resultado e corrigindo o traçado ao longo dos períodos e dos processos.

Determinar os objetivos e escolher as ferramentas adequadas é baseado em métodos e não meramente em suposições. Segundo Kotler e Armstrong (1993) e Stoner e Freeman (1995), o planejamento pode proporcionar muitos benefícios, tais como:

- $\quad$ Encorajar as organizações a pensar sistematicamente no futuro e propicia ruma melhor interação entre os seus colaboradores;

- Exigir que definissem seus objetivos e políticas; Impor a aplicação dos recursos necessários visando atender aos objetivos traçados;

- Determinar que seus colaboradores fizessem as atividades baseadas nos objetivos traçados;

- $\quad$ Padronizar as ações de desempenho, fiscalizando-as e corrigindo ao longo do percurso, caso o resultado não esteja dentro dos limites estabelecidos.

O planejamento remete a Teoria das Organizações, e evoluiu ao longo do tempo, sendo necessário contar um pouco de sua história. Desde os primórdios a Administração está presente em toda evolução humana, tendo seu início de forma racional em meados do século XX. Foi no século XVII que a razão substitui a tradição, na busca constante para solução dos problemas. Nesta época os administradores iniciaram as tentativas de previsão do futuro, organização das tarefas e processos, aplicando uma metodologia e controlando o desenvolvimento do trabalho.

A preocupação era com a eficiência das empresas devido ao inicio de uma competitividade que se acirrou ao longo do tempo. Taylor foi o precursor da organização metódica do trabalho. Na Administração Científica o planejamento surgiu para eliminar o improviso e a falta de estratégia das empresas. Sua diretriz estabelecia métodos mais adequados para o processo produtivo, com o objetivo de otimizar os recursos e aumentar a sua eficiência, que por sua vez, garantia um maior rendimento. 
De acordo com Berhr e Lima (1999) a Administração Científica, mencionava a previsão orçamentária e separava o trabalho manual do intelectual, objetivando alcançar da melhor forma possível as metas e objetivos traçados pelas organizações. Fayol grande estudioso dos processos administrativos defendia o planejamento como uma das ferramentas mais importantes da administração. Nela incluía que a previsão, o controle e o comando eram vitais para o planejamento das ações tomadas pelas organizações.

Este grande movimento levou aos autores das Relações Humanas, a defenderem que o ser humano deveria ser valorizado, e não apenas os processos administrativos. Estas necessidades estavam ligadas ao desempenho das organizações, que para alcançar seus objetivos foram obrigadas a valorizar o trabalhador, preocupando com aspectos psicológicos, a motivação e as necessidades humanas do trabalhador. Todo este movimento, ocultava o seu verdadeiro propósito, que era aumentar a eficiência organizacional.

O planejamento apesar de todo movimento humanista, permanecia com seu caráter formal, pois objetivava estabelecer as diretrizes administrativas. Outra preocupação era o ambiente externo, que atingia diretamente as organizações à medida que a concorrência aumentava, seja ela por fatores de qualidade ou por determinações governamentais. Esta visão foi incorporada, pois o ambiente externo mostrou que era importante ter holística, ou seja, enxergar a empresa com um sistema que se relaciona com o ambiente externo, ganhando um caráter analítico e determinista.

Segundo Lunkes (2003, p.35) a palavra “orçamento está ligada a uma situação popular, onde diz que é uma bolsa de tecido chamada fiscus, que foram utilizadas para coleta de impostos, pelos antigos Romanos". Consta que no passado a bolsa foi utilizada pelos funcionários e pelas tesourarias. O termo era conhecido na França como bougue ou bouguete e entre os anos de 1400 e 1450 o termo bougell foi inserido no dicionário inglês. Em 1689 com o desenvolvimento da Constituição inglesa, houve o início das atividades de orçamento.

O primeiro Ministro do Parlamento Inglês, tinha por hábito transportar os planos de despesas em uma grande bolsa confeccionada em couro, cujo cerimonial foi batizado de "opening of the budget". Esta palavra foi incluída no dicionário inglês em 1800 e "a terminologia inglesa budget é a mais utilizada entre as empresas transnacionais e se refere ao orçamento dentro do conceito estático". (PADOVEZE, 2012, p. 205).

As praticas de orçamento publico foi introduzida nos Estados Unidos no início do século XX, com menção de novos conceitos e praticas para planejamento de administração das finanças das organizações. Nova York foi à cidade pioneira na implantação do orçamento público.

No inicio da Revolução Industrial, umas séries de modificações foram feitas nas praticas de acompanhamento de dados e informações das empresas, pois, com o crescimento rápido e acúmulo de capital os administradores se viram obrigados a mecanizar os processos. Diante do aquecimento de mercado, altas somas eram destinadas ao processo fabril, visando o aumento da produção e também a contratação de mão de obra, garantindo assim maiores estoques de produtos para atender a demanda. Esta transformação foi marcada com a abertura de várias indústrias, dentre elas; as têxteis, siderúrgica e ferrovias. 
A rápida evolução industrial disparou no mercado mecanismos para aprimoramento das transações, exigindo do mercado de telefonia e transportes uma transformação para dar suporte às atividades latentes. Grandes cadeias varejistas tiveram seu auge nesta época. Os empresários criaram internamente uma forma de avalizar seu desempenho usando indicadores próprios.

A contabilidade avançou e se aprimorou para dar suporte à escrituração das empresas que carecia de um maior controle de seus documentos e planilha interna, compilando dados importantes para a tomada de decisão. A importância das ferramentas de orçamento visa nortear o processo de decisão não só do ramo empresarial, como também de todos os seguimentos e áreas, inclusive o controle de finanças familiar. A falta de eficiência nos negócios tem gerado a falência de muitas empresas e inibido o crescimento de outras. Também seguimentos que dependam de planejamento e orçamento para garantir a viabilidade e manutenção de patrimônios.

O improviso e a famosa intuição têm gerado descompasso nas finanças de muitas empresas, pois poucas trabalham de forma organizada e planejada com vista ao uso de ferramentas técnicas para tomada de decisão. Assim, ferramentas gerenciais e contábeis compõem as técnicas necessárias para uma administração coerente e lucrativa.

\section{CONCEITOS}

O orçamento é tão importante e a necessidade dele é muito antiga. Os primitivos já experimentavam a necessidade de prever, pois precisavam armazenar comida por longos períodos e esta fase foi o inicio da pratica de orçamento. Orçar é parte integrante do sistema de administração em todas as empresas.

Orçar significa processar todos os dados constantes do sistema de informação contábil de hoje, introduzindo os dados previstos para o próximo exercício, considerando as alterações já definidas para o próximo exercício. (PADOVEZE, 2012, p. 199)

O principal objetivo do orçamento está fundamentado em princípios do planejamento, do controle orçamentário, do controle do resultado através de operações formais das empresas. Welsch $(1973$, p.27) conceitua orçamento como:

Um plano administrativo abrangendo todas as fases das operações para um período futuro definido. É a expressão formal das políticas, planos, objetivos e metas estabelecidas pela alta administração para a empresa como um todo, bem como para uma das suas subdivisões. O orçamento exprimi planos relativos a itens, tais como: Níveis de estoques, acréscimos de capital, necessidades de caixa, financiamento, planos de fabricação, planos de compras, necessidades de mão-de-obra, e assim por diante. 
Rapidamente o orçamento tornou se um elemento importante para o sistema de gestão. Ele permite um gerenciamento central, exigindo disciplina financeira entre os departamentos. O planejamento orçamentário é estudado e colocado em pratica ao decorrer do ano, e caso necessário haverá alterações ao longo do curso.

Baseado na estrutura organizacional em uma primeira fase executa se a projeção dos recursos. O plano projetado visa atender as necessidades das atividades do próximo período. Em um segundo momento, o orçamento necessitara de revisão continuada removendo o período que já passou e acrescentando os períodos seguintes. Alguns modelos de orçamento podem ser trabalhados partindo do zero onde os administradores ou gestores, estimam a necessidade dos gastos e as justificam. Segundo Lunkes (2003), 'O orçamento flexível é projetado para cobrir uma gama de atividades, portanto, pode ser usado para estimar custos a qualquer nível de atividades".

O orçamento utiliza como base a informação sobre o direcionamento da empresa, os custos de planejamento e o objetivo a ser atingido. É um modelo formado por um conjunto de princípios que servem de guias para atuação da empresa.

Segundo Padozeve (2012, p. 206), “o sistema orçamentário compreende o conjunto de pessoas, tecnologia administrativa, sistemas de informação, recursos materiais disponibilizados e administração do sistema para execução dos planos orçamentários".

O orçamento empresarial visa distribuir os recursos financeiros de forma coerente e racional, visando atingir os objetivos da empresa. Assim a administração financeira destes recursos garantirá que a empresa se manterá no curso certo, atingindo assim seus objetivos de lucratividade, tomando decisões assertivas que garantam a estabelecer competitividade diante seus concorrentes, ampliando sua atuação.

Neste sentido, Gitman (2004) destaca que o objetivo da administração financeira está ligado ao objetivo da empresa: maximização de seus lucros e de seus acionistas. Sua função é criar mecanismos de análise e controle, para orientar e influenciar nas tomadas de decisão que resultem em maior retorno financeiro para a empresa. Quando as condições de mercado estão estáveis, a assertividade dos orçamentos elaborada anualmente atinge grande percentual e funcionam bem. Os custos refletem os gastos internos, as finanças e as estratégias.

Segundo Hope e Fraser (1999, p.24), "os orçamentos anuais, podem não proporcionar ao gestor, estimativas seguras, e geralmente as metas precisam de revisões que se tornam rapidamente obsoletas" e Braga (1998, p.23) afirma que "a função financeira compreende um conjunto de atividades relacionadas com a gestão dos fundos movimentados por todas as áreas das empresas".

A centralização excessiva na condução dos objetivos orçamentários coíbe a participação dos colaboradores. Assim para a Hope e Fraser (1999, p.24), "os orçamentos são baseados na centralização da gestão e assim atrapalham as tentativas de mudanças organizacionais, como: gerenciamento em equipe, delegação e empowerment". 
Padoveze (2012, p. 201) descreve que "o ponto fundamental é que orçamento deve estar totalmente integrado com a cultura empresarial", assim "orçamento deve conter as doses adequadas de participação e/ou determinação, decorrentes de sua cultura, sem prejuízo do comprometimento deste ferramental de controladoria".

O orçamento, segundo Zdanowicz (1989, p. 22) é uma técnica para o planejamento sistemático, que visa resguardar a segurança dos negócios das empresas, além de proporcionar ao administrador informações e dados para comparações freqüentes entre os resultados obtidos, valores e quantidades esperadas.

\title{
5. A EVOLUÇÃO DO OÇAMENTO EMPRESARIAL
}

A evolução do orçamento empresarial e suas técnicas contábeis tem sua trajetória firmada de maneiras diferentes, apesar de suar origem se da mesma época. No início de 1760 na Inglaterra foi desenvolvido e elaborado o orçamento, na intenção de controlar os gastos governamentais (THEISS, 1937 apud PERERA, 1998).

\begin{abstract}
Nesse sentido ponderando sobre a evolução do orçamento, Pereira (1998, p.4), pontua que $\mathrm{o}[. .$.$] orçamento tem uma história tão longa quanto às técnicas de contabilidades$ gerencial que são largamente utilizadas nas organizações contemporâneas. Enquanto as técnicas de contabilidade gerencial, tais como, retorno sobre investimento e lucro residual foram desenvolvidas, após os negócios terem aumentado em escala e complexidade, o orçamento evolui com as atividades decorrentes dos negócios.
\end{abstract}

O orçamento evolui nos Estados Unidos, passando a ter um papel importante, meados de 1900 a 1930. Suas ferramentas tais como: avaliação de desempenho, controle, coordenação e planejamento começam a ser utilizada por todas as empresas da época.

A contabilidade de custos influenciou diretamente o desenvolvimento do orçamento. Marquette e Fleischman (1992) apud Pereira (1998 p. 7) argumentaram que o “(...) desenvolvimento dos métodos contábeis e de custos podem ser considerados como um fator determinante, facilitando o incremento e uso extensivo dos orçamentos como mecanismo de controle".

Para que o orçamento empresarial fosse reconhecido, foi necessário desenvolver uma técnica metodológica, com implantação de diversos procedimentos padronizados que serviram de base orçamentária, levando em consideração cada setor empresarial. A prática orçamentária exige a integração de diversos conceitos técnicos de administração, tais como: orçamentos flexíveis, planejamento estratégico, fluxo de caixa e custo. 


\section{ESTUDO DE CASO}

O Intuito desse trabalho foi estudar a importância das ferramentas de planejamento e controle orçamentário para toda e qualquer instituição ou organização e para validar a importância da técnica orçamentária será feito um estudo de caso de um condomínio, mencionando os efeitos que a administração aplicada sem as técnicas apropriadas podem causar.

A palavra condomínio se origina dos termos em latim: "cum" conjuntamente e "dominum", domínio, ou "dominus", senhor, ou seja, propriedade em conjunto. De acordo com a Lei 4.591/64, que dispõe sobre o condomínio em edificações e as incorporações imobiliárias, o condomínio pode ser compreendido como:

Art. $1^{\circ}$. As edificações ou conjuntos de edificações, de um ou mais pavimentos, construídos sobre a forma de unidades isoladas entre si, destinadas a fim residenciais ou não residenciais, poderão ser alienados, no todo ou em parte, objetivamente considerados, e constituirá cada unidade, propriedade autônoma, sujeitas às limitações desta Lei.

Isso caracteriza uma união de pessoas, com o objetivo de manter uma propriedade comum, com direitos e deveres iguais, na proporção de sua fração ideal. O condomínio é uma propriedade, cuja unidade é privativa com o uso restrito, e suas áreas comuns são compartilhadas sendo que partes desta pertencem a todos os condôminos, não podendo ser alienadas ou divididas.

A maioria das pessoas acredita que a maior dificuldade de um Condomínio é a convivência entre vizinhos, porém, existem outros problemas tão sério quando as questões da coletividade. Apesar de um Condomínio não ser considerado uma personalidade jurídica, pois, não tem fins lucrativos, e trabalham apenas arrecadando recursos para as suas despesas, ou seja, apenas dividem os seus custos, é importante administrá-lo com ferramentas e técnicas administrativas e financeiras. Segundo Padoveze (2012, p.199) afirma que "o orçamento é ferramenta de controle por excelência de todo o processo operacional da empresa, pois envolve todos os setores da companhia".

A administração financeira de um Condomínio é muito importante, não só para o equilíbrio financeiro, quanto para a valorização do imóvel. Quando suas despesas não são mesuradas corretamente, eleva-se o rateio da cota condominial a ponto de fazer o imóvel perder o seu valor comercial, aumentar a inadimplência e reduzir a satisfação dos moradores.

As técnicas usadas para a administração de uma empresa ou organização deve ser aplicada na gestão de um condomínio. Aplicar a prática orçamentária é muito importante e garantirá um acompanhamento real de suas despesas e investimentos. O Condomínio sobrevive basicamente do rateio de suas despesas totais, convertidas em frações ideais e aplicada a todas as unidades. Estes valores precisam ser bem analisados, pois farão frente aos compromissos assumidos pelo Condomínio. 
Cabe ao sindico a administração e o gerenciamento condominial. De acordo com o artigo 1347 Novo Código Civil a assembléia condominial elegera um sindico, por prazo não superior a dois anos, renováveis, podendo ou não ser condômino. O sindico pode delegar parte desta responsabilidade a terceiros, ou seja, a uma empresa especializada em administração condominial.

A grande problemática da administração condominial é muitas vezes a inexperiência ou desconhecimento por parte do sindico que não aplica as técnicas de planejamento e orçamento em sua administração. O planejamento orçamentário consiste em conhecer as necessidades e todas as despesas para a manutenção e conservação da edificação.

O gerenciamento das despesas condominiais depende de uma mensuração clara de seus custos e investimentos, alem do acompanhamento continuo de sua evolução. A aplicação do orçamento permite ao administrador uma tranqüilidade e equilíbrio financeiro. Calculando as despesas de forma coerente e racional, é possível visualizar qualquer descompasso eventualmente gerado por aumento de consumo ou despesas extras, provenientes de rompimento de tubulação, quebra de equipamentos ou outros.

Através da previsão orçamentária é possível calcular de forma estimada os reajustes futuros, de tarifas públicas, reajuste de funcionários, rateio para $13^{\circ}$ salário e férias e outros. Importante também trabalhar com uma margem de segurança, criando um fundo de caixa para situações inesperadas, alem do fundo obrigatório.

Conforme determina a legislação, em seu artigo 22, inciso x, letra "g" da lei 8.245/91 (Lei do Inquilinato) e no artigo $9^{\circ}$, parágrafo $3^{\circ}$, alínea j, da Lei 4.591/64 o Condomínio precisa fazer uma reserva, chamada de Fundo de Reserva. Este fundo é formado por um percentual aplicado sobre a arrecadação ordinária, e é arrecadado todos os meses. A composição deste fundo deve ser aplicada separadamente das demais arrecadações, pois, permanecerá guardada para emergências de grande porte.

Apesar de o Condomínio funcionar basicamente com o fracionamento de suas despesas, devido a inadimplência, muitos condomínios têm encontrado dificuldades em equacionar as suas finanças. Os devedores são os maiores vilões das finanças de um Condomínio, pois, deixando de contribuir com sua cota condominial, o inadimplente prejudica os pagantes, onerando-os, pois o rateio da diferença entre receita e despesas, será por eles arcado.

Quando se trabalha com orçamento, estes valores são considerados. Determina-se um percentual, calculado sobre o histórico dos devedores e já se embute na arrecadação, formando uma sobra de caixa para fazer frente a inadimplência. Importante lembrar que toda unidade devedora será cobrada e um dia estes recursos retornarão ao caixa do Condomínio. As unidades devedoras serão cobradas na forma da lei, desde uma simples carta de cobrança até a utilização da esfera judicial, no melhor interesse do Condomínio.

Para formular de forma mais precisa possível uma previsão orçamentária de Condomínio, pode-se partir do histórico financeiro dos últimos doze meses, tirando a média, ou ainda, projetar suas despesas para o futuro com base nas últimas despesas. Aplicar-se sobre os números encontrados o percentual de reajuste estimado para o próximo período. 
Quando um condomínio não se utiliza da técnica orçamentária, a oscilação de sua arrecadação prejudica a todos. O imóvel perde o valor comercial, pois, nenhum interessado irá comprar um apartamento, cujas despesas não são conhecidas.

O estudo de caso é sobre um condomínio, situado em São Paulo, cujo codinome será Esperança. Este condomínio foi diagnosticado tecnicamente como "falido". Suas finanças estavam completamente desajustadas e o condomínio já acumulava um saldo bancário devedor utilizando se do cheque especial cuja taxa de juros era altíssima. O condomínio não dispunha de qualquer documento ou planilha de controle de suas despesas. Por falta de manutenção diversos problemas de conservação do patrimônio já acarretavam sérias despesas extras, das quais os moradores não conseguiam pagar.

Constatou se também que o controle contábil era confuso e sem qualquer validade. Não havia um controle da inadimplência e das unidades devedoras. As taxas condominiais eram pagas em dinheiro e havia pouco controle sobre estas entradas. Estima-se que muitos recursos foram desviados.

Numa assembleia, os condôminos cansados dos altos e baixos do fluxo de caixa, resolveram destituir o Síndico e começar uma nova gestão com lisura. Elegeram naquela noite outro representante legal, ou seja, um Síndico e seus Conselheiros. A primeira providencia foi a dê contratar uma Administradora para fazer o trabalho administrativo de forma profissional, com todos os controles contábeis e financeiros. Abriu se uma conta bancária para o Condomínio e todos os boletos de cota condominial passou a ser registrado pelo banco.

Iniciou se então uma análise aprofundada das necessidades financeiras da instituição bem como um levantamento técnico através de um engenheiro das necessidades de manutenção da estrutura da edificação. Apurou se os custos reais para a conservação de suas estruturas e para fazer frente aos compromissos assumidos.

$\mathrm{Na}$ sequencia foram estudadas todas as despesas do Condomínio e através da técnica de orçamento, montou-se uma planilha de previsão orçamentária sólida. Conforme Gitman (2004) a função do orçamento é criar mecanismo de analise de controle, para orientar e influenciar as tomadas de decisão que resultem em maior rentabilidade para a empresa, neste caso o melhor acompanhamento financeiro para o condomínio.

Através do controle orçamentário observou se gastos muito elevados nas contas de consumo, tais como água, luz e gás, além de uma folha de pagamento incompatível com as aplicadas no mercado naquela data. Diante deste resultado algumas estratégias foram elaboradas visando à redução de gastos.

Os ganhos que o condomínio começou a ter vão em sintonia que Padoveze (2012, p. 283) dizia que a base do controle orçamentário é o confronto dos dados orçados contra os dados reais obtidos pelo sistema de informação contábil. As variações ocorridas entre os dados reais e os orçados permitirão uma séria de análises, identificando se as variações ocorridas foram decorrentes de plano, preço, quantidade, eficiência etc. 
O planejamento destas despesas passou por uma avaliação onde identificou se os pontos de maior desperdício. Inicio se então uma campanha de conscientização da coletividade para o uso consciente e eficiente destes recursos. Utilizando essas ferramentas administrativas importantes foi possível a tomada de decisão por parte do sindico e conselheiros de forma eficaz, aplicando os recursos nos pontos mais importantes e equacionando as despesas visando o maior controle de gastos mantendo a previsão orçamentária original.

Com o passar do tempo o caixa do condomínio de recuperou, houve uma diminuição da inadimplência e hoje o condomínio dispõe de recursos aplicados em fundo de investimento para eventuais emergências, além dos recursos financeiros do Fundo de Reserva, obrigatório, conforme determina o Código Civil e a Convenção Condominial, devidamente preservado e também aplicado.

O controle de gastos foi fundamental para organizar a vida administrativa do edifício, bem como a de seus moradores que hoje sabem exatamente o que vão pagar, em boletos bancário, fixos por dozes meses e reajustados a cada ano com base no controle orçamentário.

O controle financeiro e a mais tradicional forma de controle do desempenho organizacional. Isso porque, além de os recursos financeiros serem um parâmetro de fácil mensuração e controle, o objetivo final da maioria das organizações é a geração de lucros. (SOBRAL e PECI, 2008, p. 242).

Os apartamentos estão valorizados, o Condomínio com suas estruturas preservadas e bem cuidadas, todas as manutenções em dia, toda a documentação em perfeita ordem, de acordo com a legislação vigente e o melhor, a harmonia dos moradores que sentem confiança em contribuir com sua taxa condominial, pois tem a satisfação de morar bem e com a garantia de poder comercializar sem imóvel, sem qualquer prejuízo.

\section{CONSIDERAÇÕES FINAIS}

A finalidade desta pesquisa foi ratificar a importância do planejamento e orçamento dentro de toda e qualquer organização. As técnicas orçamentarias garantem a metodologia correta para executar um planejamento e previsão financeira de modo a alcançar os objetivos traçados dentro dos parâmetros estabelecidos.

A premissa é a de provisionar recursos suficientes para o planejamento anual evitando ser surpreendido por despesas ou ocorrências não estimadas em sua previsão orçamentária. $\mathrm{O}$ objetivo é a de contemplar muito próximo da realidade financeira todos os custos que serão envolvidos para a manutenção da organização ou negócio. 
Durante o estudo de caso foi possível observar o quanto uma administração sem critérios pode prejudicar os envolvidos no processo ou na organização. Uma previsão orçamentária bem elaborada, contemplando todos os índices, através de projeção e indicadores de possíveis gastos futuros, auxilia de forma coerente a composição do fluxo de caixa periódico.

Diante de toda técnica estudada concluímos que o planejamento e orçamento evita prejuízos a organização, cria bases para a tomada de decisão com alto percentual de assertividade e maior controle orçamentário, auxiliando o alcance das metas estabelecidas e de seus resultados. Com o sucesso obtido pelo planejamento e orçamento correto a organização torna se confiante para avançar em seu projeto viabilizando um futuro promissor, lucrativo ou satisfatório atingindo seu objetivo final.

\section{REFERÊNCIAS}

BEHR, Ricardo Roberto; LIMA, Afonso Augusto Teixeira de Freitas de Carvalho. Participação, criatividade e planejamento estratégico. [online]. Bauru: nov. 1999. Anais do VI Simpósio de Engenharia de Produção.

BRAGA, Roberto. Fundamentos e Técnicas de Administração Financeira. São Paulo; Atlas, 1989.

GITMAN, Lawrence Jeffrey. Princípios da Administração Financeira, 10 ${ }^{\mathrm{a}}$ Edição. - São Paulo: Person Addison Wesley, 2004.

HOPE, J.; FRASER, R. B. The Hidden Barrier to Success in the Information Age. Accounting \& Business, 1999.

KOTLER, Philip; ARMSTRONG, Gary. Princípios de Marketing. Rio de Janeiro: Prentice Hall do Brasil, 1993.

LEITE, Rita Mara; CHEROBIM, Ana Paula Mussi Szabo; SILVA, Helena de Fátima Nunes e BUFREM, Leilah Santiago. Orçamento empresarial: levantamento da produção científica no período de 1995 a 2006. Rev. contab. finanç. [online]. 2008, vol.19, n.47, pp. 56-72. ISSN 1808-057X.

LUNKES, Rogério, João. Manual do Orçamento. São Paulo; Atlas, 2003.

PADOVEZE, Clóvis Luiz. Controladoria Estratégica e Operacional: conceitos, estrutura, aplicação. 3. ed. rev. e atual. - São Paulo: Cengage Learning, 2012. 
PERERA, S. The historical development of business budgeting: an organizational perspective. Accounting Forum, v. 22, n. 1, p. 3-13, jun. 1998

STONER, J. A. F; FREEMAN, R. E. Administração. 5. Ed. Rio de Janeiro: Prentice Hall do Brasil, 1995.

SOBRAL, Filipe; PECI, Alketa. Administração: teoria e prática no contexto brasileiro. São Paulo: Pearson Prentice Hall, 2008.

WELSHE, Glean. A. Orçamento Empresarial. São Paulo: Atlas, 1973.

ZDANOWICZ, José Eduardo. Orçamento Operacional. $3^{a}$ Ed. Porto Alegre: D. C. Luzzato Editores Ltda, 1989. 